\title{
Computer-Based Drug-Utilization Review - Risk, Benefit, or Boondoggle?
}

\section{Citation}

Soumerai, Stephen B., and Helene L. Lipton. 1995. "Computer-Based Drug-Utilization Review Risk, Benefit, or Boondoggle?" New England Journal of Medicine 332 (24) (June 15): 1641-1645. doi:10.1056/nejm199506153322411.

\section{Published Version}

doi:10.1056/NEJM199506153322411

\section{Permanent link}

http://nrs.harvard.edu/urn-3:HUL.InstRepos:32692607

\section{Terms of Use}

This article was downloaded from Harvard University's DASH repository, and is made available under the terms and conditions applicable to Other Posted Material, as set forth at http:// nrs.harvard.edu/urn-3:HUL.InstRepos:dash.current.terms-of-use\#LAA

\section{Share Your Story}

The Harvard community has made this article openly available.

Please share how this access benefits you. Submit a story.

\section{Accessibility}




\section{HORMONE-REPLACEMENT THERAPY - BREAST VERSUS HEART VERSUS BONE}

THANKs to many public health advances, in the developed countries the average woman will be postmenopausal for about one third of her life. As a consequence, she and her physician will ultimately need to make a decision about postmenopausal estrogen-replacement therapy. This treatment has been used for several decades, but there is a surprising lack of consensus about when and how to use it. The initial goal of estrogenreplacement therapy was to alleviate menopausal symptoms. More recently, the possibility has emerged that estrogen can reduce morbidity and mortality from ischemic heart disease and osteoporosis. However, women and their physicians must balance these apparent benefits against the possibility that estrogen therapy might increase the incidence of cancer of the breast and uterus or mortality from these diseases. ${ }^{1}$

The situation has been further muddled by the increasing use of hormone-replacement therapy — that is, estrogen and a progestin in combination. This practice reflects unequivocal evidence linking unopposed estrogen therapy to endometrial hyperplasia and cancer, pathologic changes that are prevented by the cyclic or continuous administration of a progestin. Indeed, this risk of estrogen therapy was confirmed in the recent report of the Postmenopausal Estrogen/Progestin Interventions (PEPI) trial, a three-year randomized trial of placebo, unopposed estrogen, or three estrogenprogestin regimens in 875 postmenopausal women. ${ }^{2}$ This study found that the risk of adenomatous or atypical endometrial hyperplasia was about 1 percent among women randomly assigned to placebo or to any of the estrogen-progestin combinations, whereas it was 34 percent among women assigned to treatment with estrogen alone. Endometrial cancer was not an end point of the trial, but evidence from other sources shows an increase of up to sixfold in the incidence of endometrial cancer among women receiving estrogen-replacement therapy ${ }^{3}$; the concurrent use of a progestin markedly reduces this risk. Thus, the use of estrogen and a progestin combined is increasing among postmenopausal women with an intact uterus who decide to begin replacement therapy.

What about hormones and the breast? Epidemiologic studies and studies in animals strongly implicate estrogen in the development of breast cancer. Recent metaanalyses of data on estrogen-replacement therapy and the risk of breast cancer suggest that there is little risk associated with past use or short-term use of estrogen, but it has been estimated that the risk of breast cancer after 10 years of estrogen therapy is increased by 15 to 30 percent. ${ }^{4}$ Information about combined hormonereplacement therapy and the risk of breast cancer has been harder to obtain, since many studies were conducted before such therapy became commonplace. The effects of estrogen-progestin therapy on the uterus and the breast may differ considerably. During the menstrual cycle, the mitotic activity of endometrial cells peaks during the early follicular phase (a time of increased estradiol production) and decreases during the luteal phase (a time when both estrogen and progesterone are produced). In contrast, most proliferative activity in the breast occurs during the luteal phase. Thus, estrogen plus progestin might increase the risk of breast cancer more than estrogen alone. ${ }^{5}$ Indeed, a study by Bergkvist et al. ${ }^{6}$ suggested just that - an increased risk with combined estrogen and progestin therapy, especially prolonged therapy. However, the types of estrogen-replacement therapy used in that study differed from those used in the United States, where most women receive conjugated equine estrogen.

In this issue of the Journal, Colditz et al. ${ }^{7}$ describe the effects of adding progestin to estrogen therapy in a U.S. population, the Nurses' Health Study cohort. The report is based on 1935 cases of invasive breast cancer identified among postmenopausal women in the parent study during 725,550 person-years of follow-up. Most women took conjugated equine estrogen, and the study spanned the decade of the 1980 s, when combined hormone-replacement therapy became substantially more common. The analysis showed that the relative risk of breast cancer was 1.32 for women who were currently receiving estrogen alone and 1.41 for women receiving estrogen plus a progestin. Thus, the addition of progestin to estrogen had no significant effect on the risk of breast cancer. The risk among past users or current users who had been taking hormones for less than five years was similar to that among postmenopausal women who had never taken hormones. However, the relative risk was 1.71 among women 60 to 64 years of age who had been receiving hormonal therapy for at least five years. The finding that the risk of death due to breast cancer paralleled the incidence suggests that these breast cancers were clinically important.

Given the disparate effects of estrogen and progestin on the breast and the uterus, what do we know about the effects of estrogen and estrogen-progestin therapy on other clinical outcomes? Ischemic heart disease is the most common cause of death among postmenopausal women in this country. Numerous observational studies suggest a 50 percent reduction in the risk of heart disease among postmenopausal women who receive estrogen-replacement therapy. ${ }^{8,9}$ Concern that progestin might weaken the protective effects of estrogen has been alleviated by the PEPI trial, which showed that estrogen-replacement therapy or combined hormone-replacement therapy improved the lipoprotein profile and lowered fibrinogen levels without appreciable effects on blood pressure or post-challenge insulin levels. However, estrogen had a more favorable effect on high-density lipoprotein cholesterol than any form of combined therapy, a noteworthy finding since this form of cholesterol is important in protecting women from atherosclerosis. The effect of these changes on the incidence of cardiac events is not known, because the study was designed to focus only on intermediate end points. ${ }^{2}$

The relative effectiveness of estrogen and estrogen- 
progestin therapy in preventing fractures is also important; preliminary results from the Study of Osteoporotic Fractures are once again reassuring. In this prospective study of 9704 women who were 65 years of age or older, the multivariate adjusted relative risk for all nonspinal fractures among current users of estrogenreplacement therapy was 0.69 (95 percent confidence interval, 0.56 to 0.86 ), as compared with 0.51 (95 percent confidence interval, 0.33 to 0.78 ) for current users of combined hormone-replacement therapy. ${ }^{10}$ These data argue against an adverse effect on the reduction of fractures in older women due to combining progestin with estrogen. Preliminary data also suggest that estrogen-replacement therapy may lower the risk of fatal colon cancer. ${ }^{11}$

Given our fragmented knowledge of therapy with estrogen alone or with estrogen plus a progestin, a prospective assessment of the net health effects of postmenopausal hormone therapy is badly needed; such an evaluation is now under way under the auspices of the Women's Health Initiative. Women who have previously undergone hysterectomy will be randomly assigned to placebo or to daily therapy with conjugated equine estrogen, and those with an intact uterus will be randomly assigned to placebo or daily conjugated equine estrogen plus medroxyprogesterone acetate. Although the primary end points are coronary heart disease and osteoporotic fractures, information about breast and colon cancer may also emerge. In the meantime, all postmenopausal women should be apprised of our current understanding of the risks and benefits of hormone-replacement therapy. They should pay particular attention to their own risk factors and the relative impact of cardiovascular disease, osteoporotic fractures, and cancer of the breast, colon, and uterus on women's health in general. ${ }^{12}$ For those who choose therapy, estrogen-replacement therapy is the optimal approach for women who have undergone hysterectomy, whereas the use of combined estrogen-progestin therapy should be considered for women with an intact uterus.

Johns Hopkins Oncology Center

Baltimore, MD 21231

Nancy E. Davidson, M.D.

\section{REFERENCES}

1. Belchetz PE. Hormonal treatment of postmenopausal women. N Engl J Med 1994;330:1062-71.

2. The Writing Group for the PEPI Trial. Effects of estrogen or estrogen/ progestin regimens on heart disease risk factors in postmenopausal women: the Postmenopausal Estrogen/Progestin Interventions (PEPI) Trial. JAMA 1995;273:199-208.

3. Antures CMF, Stolley PD, Rosenshein NB, et al. Endometrial cancer and estrogen use: report of a large case-control study. N Engl J Med 1979;300:913.

4. Steinberg KK, Smith SJ, Thacker SB, Stroup DF. Breast cancer risk and duration of estrogen use: the role of study design in meta-analysis. Epidemiology 1994;5:415-21.

5. Pike MC, Spicer DV, Dahmoush L, Press MF. Estrogens, progestogens, normal breast cell proliferation, and breast cancer risk. Epidemiol Rev 1993;15: 17-35.

6. Bergkvist L, Adami H-O, Persson I, Hoover R, Schairer C. The risk of breast cancer after estrogen and estrogen-progestin replacement. N Engl J Med 1989;321:293-7.

7. Colditz GA, Hankinson SE, Hunter DJ, et al. The use of estrogens and progestins and the risk of breast cancer in postmenopausal women. N Engl J Med 1995;332:1589-93.

8. Barrett-Connor E, Bush TL. Estrogen and coronary heart disease in women. JAMA 1991;265:1861-7.

9. Stampfer MJ, Colditz GA, Willett WC, et al. Postmenopausal estrogen therapy and cardiovascular disease - ten-year follow-up from the Nurses' Health Study. N Engl J Med 1991;325:756-62.

10. Cauley JA, Seeley DG, Ensrud K, Ettinger B, Black D, Cummings SR. Estrogen replacement therapy and fractures in older women. Ann Intern Med 1995;122:9-16

11. Calle EE, Miracle-McMahill HL, Thun MJ, Heath CW Jr. Estrogen replacement therapy and risk of fatal colon cancer in a prospective cohort of postmenopausal women. J Natl Cancer Inst 1995;87:517-23.

12. Grady D, Rubin SM, Petitti DB, et al. Hormone therapy to prevent disease and prolong life in postmenopausal women. Ann Intern Med 1992;117: 1016-37.

\section{CHIPPING AWAY AT MARBLE-BONE DISEASE}

Osteopetrosis (marble-bone disease) results from diminished skeletal resorption. ${ }^{1}$ We are certain of this pathogenesis because histologic studies of bone show that primary spongiosa - the scaffolding synthesized by chondrocytes in growth plates for subsequent deposition of osseous tissue - is not removed by osteoclasts during skeletal remodeling (turnover). Instead, this form of cartilage becomes encased as "islands" within trabecular bone and persists away from sites of endochondral bone formation. Bone formation continues normally, and the bones become increasingly dense. ${ }^{1}$

When skeletal resorption is profoundly impaired, the neural foramina do not widen, the medullary space is choked with bone, and skeletal remodeling is slowed. Consequently, severely affected patients suffer cranialnerve entrapment, bone marrow failure, and recurrent fractures. ${ }^{1}$

Two types of osteopetrosis are generally known - an infantile ("malignant") form and an adult ("benign") form that are inherited as autosomal recessive and autosomal dominant traits, respectively. ${ }^{2}$ Untreated, the infantile type is usually fatal during the first decade of life; patients die of infection, hemorrhage, or profound anemia. ${ }^{1}$

Palliative therapy for osteopetrosis includes the administration of a glucocorticoid to improve the hematologic consequences of extramedullary hematopoiesis. ${ }^{3}$ More specific treatment, however, focuses on increasing skeletal breakdown. Since osteoclasts mediate bone resorption, these multinucleated cells are the appropriate target of experimental regimens. Indeed, histopathological study of the bones of patients with infantile osteopetrosis usually shows an abundance of osteoclasts. ${ }^{1}$ Nevertheless, some straightforward approaches to stimulating osteoclasts have not been very successful - for example, injection or increased secretion (caused by the ingestion of a calcium-deficient diet) of parathyroid hormone. ${ }^{1,3}$

Fortunately, there are a variety of animal models of 
osteopetrosis. $^{2}$ In 1972, Donald G. Walker made the important discovery that grey-lethal mice are cured by temporary parabiosis to normal littermates. Thus, a circulating cell or factor can permanently correct this disorder. ${ }^{4}$ Subsequently, he showed that the intravenous administration of cell suspensions prepared from the bone marrow or spleens of unaffected littermates had the same effect. His work revealed that osteoclasts in this murine model of osteopetrosis are derived from a cell of hematopoietic origin that circulates. ${ }^{4}$

In 1977, bone marrow transplantation improved a number of manifestations of osteopetrosis in an infant girl. Subsequently, this treatment has reversed the complications of the disease in a convincing number of severely affected patients. There is evidence from the success of this treatment that osteoclasts in humans are derived from bone marrow precursor cells. ${ }^{1}$ Nevertheless, allogeneic marrow transplantation has risks for the recipient and is technologically demanding and expensive. Furthermore, HLA-matched donors are important for a successful outcome. In a study of $69 \mathrm{pa}-$ tients, primarily in Europe, 79 percent of those who received marrow from HLA-identical sibling donors were alive with osteoclast function five years after transplantation, but the outcome was much poorer with less favorable HLA matches. ${ }^{5}$

Where do we look for new treatments of osteopetrosis? Laboratory studies make it clear that osteoclast development is complex and that skeletal resorption is highly regulated. ${ }^{6}$ Mononuclear cells of monocytemacrophage lineage in the marrow or the blood attach to osseous tissue and fuse to become multinucleated osteoclasts. These cells are then influenced by a complex milieu of systemic and local factors to secrete the hydrochloric acid and proteases that dissolve bone. ${ }^{6}$

In this issue of the Journal, Key and coworkers report that long-term therapy with recombinant interferon gamma-lb is beneficial in patients with infantile osteopetrosis. ${ }^{7}$ The rationale for this therapy was the observation that circulating leukocytes in these patients had a decreased ability to oxidize nitroblue tetrazolium. ${ }^{8}$ After interferon gamma was found to correct this defect in patients with chronic granulomatous disease, Key and colleagues undertook pilot studies with this agent in patients with osteopetrosis. ${ }^{7}$

In the current report by Key et al., a heterogeneous group of severely affected patients with osteopetrosis (some receiving calcitriol treatment, some fed a calcium-deficient diet, and some in whom bone marrow transplantation had failed) were treated with interferon gamma-1b for up to 18 months. This long-term therapy was usually associated with improvement in a variety of manifestations of the disease, including anemia, thrombocytopenia, and osteosclerosis. Furthermore, the patients had a considerable decrease in the frequency of infections. Although the study was not controlled, the changes in this group of patients with an otherwise dismal prognosis seem convincing and are clinically im- portant. Unfortunately, interferon gamma-1b therapy is expensive and is not free of side effects. ${ }^{7}$

There are intriguing questions concerning this treatment. Why is the production of superoxides by circulating monocytes deficient, and precisely how does interferon gamma-lb enhance superoxide production? What is the mechanism by which interferon gamma- $1 \mathrm{~b}$ overcomes the osteoclast defect and enhances bone resorption?

The bad news from Key and colleagues is that another promising medical therapy for osteopetrosis seems eventually to become ineffective in some patients. These investigators previously reported that calcitriol, which stimulates osteoclasts in vitro, ${ }^{6}$ and a calcium-deficient diet partially ameliorated the defective skeletal resorption and osteosclerosis that characterize congenital osteopetrosis. ${ }^{3}$ We now learn that some patients become refractory to this regimen. ${ }^{7}$

There appear to be at least nine forms of human osteopetrosis. ${ }^{1,2}$ Most are heritable. However, only carbonic anhydrase II isoenzyme deficiency - formerly called the syndrome of osteopetrosis, renal tubular acidosis, and cerebral calcification - is understood at the molecular level. ${ }^{1,2}$ It is clear that the causes of osteopetrosis in humans are diverse and that a single therapeutic approach is not likely to benefit all patients. In fact, Key and coworkers found that, despite increased superoxide production, not all their patients responded to interferon gamma-1b.

Improved understanding of the causes and mechanism of the defective action of osteoclasts in patients with osteopetrosis will be necessary to improve therapy. Key and colleagues have shown us a way to decrease the burden of unremodeled bone in a small population of patients with infantile osteopetrosis. It appears that at least some types of marble bone can be sculpted with interferon gamma-1b.

Washington University

School of Medicine

St. Louis, MO 63110

Michael P. Whyte, M.D.

\section{REFERENCES}

1. Whyte MP. Osteopetrosis and the heritable forms of rickets. In: Royce PM, Steinmann B, eds. Connective tissue and its heritable disorders: molecular, genetic, and medical aspects. New York: Wiley-Liss, 1993:563-89.

2. Idem. Recent advances in osteopetrosis. In: Cohn DV, Gennari C, Tashjian $\mathrm{AH} \mathrm{Jr}$, eds. Calcium regulating hormones and bone metabolism: basic and clinical aspects. Vol. 11. International congress series 1003. Amsterdam: Excerpta Medica, 1992:420-30.

3. Key LL Jr, Ries WL. Osteopetrosis: the pharmaco-physiologic basis of therapy. Clin Orthop 1993;294:85-9.

4. Walker DG. Bone resorption restored in osteopetrotic mice by transplants of normal bone marrow and spleen cells. Science 1975;190:784-5.

5. Gerritsen EJ, Vossen JM, Fasth A, et al. Bone marrow transplantation for autosomal recessive osteopetrosis: a report from the Working Party on Inborn Errors of the European Bone Marrow Transplantation Group. J Pediatr 1994; 125:896-902.

6. Manolagas SC, Jilka RL. Bone marrow, cytokines, and bone remodeling emerging insights into the pathophysiology of osteoporosis. N Engl J Med 1995;332:305-11.

7. Key LL Jr, Rodriguiz RM, Willi SM, et al. Long-term treatment of osteopetrosis with recombinant human interferon gamma. N Engl J Med 1995; 332:1594-9.

8. Reeves JD, August CS, Humbert JR, Weston WL. Host defense in infantile osteopetrosis. Pediatrics 1979;64:202-6. 


\section{SOUNDING BOARD}

\section{COMPUTER-BASED DRUG-UTILIZATION REVIEW - RISK, BENEFIT, OR BOONDOGGLE?}

ON October 28, 1990, with little debate, Congress passed the Omnibus Budget Reconciliation Act, requiring the states to provide claims-based drug-utilization review to approximately 34 million Medicaid enrollees. ${ }^{1,2}$ The provisions of the program were borrowed from the ill-fated Medicare Catastrophic Coverage Act of 1988, repealed in 1990; the stated goals were to reduce potentially inappropriate prescribing and dispensing of medications, enhance the counseling of patients, and reduce growth in expenditures for drugs. ${ }^{1}$ Drugutilization review is a structured, ongoing program that interprets patterns of drug use in relation to predetermined criteria and attempts to prevent or minimize inappropriate prescribing. ${ }^{3,4}$ Thus, it resembles other programs reviewing the appropriateness of medical procedures, including surgery and hospital admissions. As in the case of drug-utilization review, there is substantial debate about the cost and effectiveness of such programs. ${ }^{5-8}$

Drug-utilization review may be conducted retrospectively or prospectively, and the 1990 act mandated both types. A prospective review is designed to enable pharmacists to detect potential problems with drug therapy before they dispense medications. Currently, most pharmacists in the United States provide such a review on site: they maintain histories of their customers' prescriptions, often using computerized screening systems unique to their own pharmacies. It is estimated that by the end of 1995 about half the states will have prospective programs on line. ${ }^{9}$ These programs use standardized software to detect potential drug-therapy problems and have access to centralized information about a patient's prescription history, regardless of where the patient purchased the medication. The 1990 act required that criteria be developed to identify problems in certain categories, including inappropriate dosage (e.g., an excessive daily dose of oxycodone with acetaminophen), overuse (early refills), underuse (late refills), duration of therapy, duplication of therapy, indications or contraindications, and interactions between drugs (e.g., carbamazepine with lithium). These criteria had to be drawn from drug compendiums specified in the 1990 legislation or from the peer-reviewed literature. If the patient's prescription violated the criteria, the pharmacist was required to determine (sometimes by calling the prescribing physician) whether to dispense it as written, to adjust the prescription, or to dispense no prescription.

A retrospective drug-utilization review, which is conducted after medications are dispensed, usually checks claims data to identify potentially inappropriate prescriptions for individual patients. If the computer program finds that a physician's prescription for a partic- ular patient has violated the criteria for optimal drug use (e.g., the use of long-acting benzodiazepines for elderly patients), the case is reviewed by a panel of physicians and pharmacists. If the panel finds the prescription problematic, it sends an advisory letter asking the physician to change it.

All Medicaid programs nationwide are now engaged in either retrospective or prospective review of this type. At least half the retrospective programs are operated by private firms. In the private sector, the prescriptions of an estimated 75 percent of Americans with outpatient drug insurance are scrutinized. ${ }^{10}$ Given this degree of penetration in both the private and public sectors, it is important to consider several fundamental questions if these systems are to improve the quality and efficiency of care.

We focus here on the most widespread application of drug-utilization review: the use of administrative-claims data bases to alert physicians and pharmacists to problems with prescriptions for individual patients. The 1990 Omnibus Budget Reconciliation Act encourages states to develop educational programs that include face-to-face counseling for physicians with a demonstrated need for specific advice about drug prescriptions. ${ }^{11}$ Interventions of this type and other means of improving aggregate prescribing practices ${ }^{12}-$ feedback to groups of physicians on their adherence to therapeutic guidelines, recruitment of physicians who are local opinion leaders to educate their peers, and the like - are beyond the scope of this article.

We believe that some forms of computer-based drugutilization review, however well-intentioned, have been implemented without satisfactory evidence of their efficacy and safety. Current programs focus on errors of commission, without examining problems of underuse; they also emphasize savings in the short-term (e.g., reductions in doses or refills of costly medications) rather than longer-term efforts to achieve systemwide savings (e.g., reduced rates of hospitalization due to increased compliance with antihypertensive regimens). In the private sector, recent acquisitions by drug companies of firms that conduct drug-utilization reviews may pose conflicts of interest. We conclude with recommendations for improvement in the scientific foundation of drug-utilization review as well as in private and public policies.

\section{Lack of Supporting Data}

Claims that drug-utilization review is cost effective because it reduces the incidence of drug-related illness and hospitalization tend to be inflated and based on unpublished, poorly controlled, or biased studies. ${ }^{13,14}$ Few evaluations of commercial programs have been published, ${ }^{15}$ because of the proprietary nature of the programs. ${ }^{16}$ Typically, retrospective studies have merely determined how often problematic drugs are discontinued, often months after physicians have received a peer-review letter. ${ }^{17}$ The studies measure success by the percentage of cases in which drug-therapy decisions are 
altered, ${ }^{17}$ but they do not explore other possible explanations (e.g., that physicians may have changed their prescribing behavior before the peer-review letter was sent). ${ }^{3}$ These weak research designs suffer from many biases, including regression to the mean, which tends to exaggerate the effects of the review program. ${ }^{18}$

Few controlled studies have examined the direct effect of drug-utilization review on patients' outcomes, such as the use of hospitals. A notable exception is a recent controlled study of the Medicaid program in California, ${ }^{19}$ which revealed that retrospective review in several counties brought no changes in costs for health care or prescription drugs. The negative results may have been due to the small percentage of prescriptions flagged by the computer that resulted in letters to physicians; to a lack of diagnostic information, so that the appropriateness of prescriptions could not be determined; or to inability to identify the prescribing physician for about one fourth of patients.

To Congress's credit, the 1990 law authorized funding to evaluate counseling by pharmacists and prospective drug-utilization review; demonstration projects in Iowa and Washington, funded by the Health Care Financing Administration, will be completed by 1996 . The Iowa project will test whether prospective drugutilization review is cost effective and will examine outcomes, including the frequency with which potential drug-therapy problems (i.e., failure of the prescribing physician to adhere to computerized criteria) are detected, the percentage of such problems that lead to an intervention by the pharmacist, and changes in hospital admissions for drug-induced illness. The Washington project will test whether reimbursing pharmacists for their counseling services increases the detection of problems, raises the number of interventions by pharmacists, and reduces the costs of drug therapy.

\section{Questionable Screening Criteria}

The efficacy of computer-based drug-utilization review depends largely on the plausible assumption that greater adherence to the many published criteria regarding drug interactions, excessive dosages, and other potential drug-therapy problems will reduce the incidence of serious adverse effects, such as drug-related hospitalizations. With a few exceptions,${ }^{20}$ however, there is little evidence to support this assumption. Lack of validation of the screening criteria is one of the most serious deficiencies of utilization review, for both drugs and medical care. ${ }^{8}$ To the extent that physicians receive conflicting information about the same therapeutic problem from different companies, the review process will be no more helpful than much of the prescribing information they have received in the past (e.g., from multiple pharmaceutical companies). ${ }^{11}$ Recent analyses suggest that the review criteria obtained from five authoritative drug compendiums differ substantially in content and scope. For example, among 26 possible interactions between digoxin and other drugs, the five compendiums agreed with respect to the existence and severity of only 1 (that between digoxin and quinidine) (Byrns PJ et al.: unpublished data). Not all of the compendiums agreed about the interaction of digoxin with verapamil, amply demonstrated by studies published in peer-reviewed journals. ${ }^{21-23}$

Concurrence between computer-derived alerts of potential problems with drug therapy and expert opinions has been as low as 10 percent, suggesting that many such alerts are false positives. ${ }^{24-26}$ In a concurrent system of physician feedback operated by a commercial utilization-review firm (evaluated by one of us in a controlled trial $\left.^{26}\right)$, clinicians thought that the vast majority of messages generated by the computer were invalid or not clinically important for particular patients. In the words of one physician, "The system provided too much detail about drug-therapy problems that we already know about or about drug-therapy problems that were clinically insignificant." The warning messages focused on drugs that are commonly accepted as relatively safe in most situations (e.g., antiulcer drugs). Furthermore, the system provided warnings without giving information on the estimated frequency of specific serious side effects; thus, clinicians could not weigh these risks against the benefits or consider other therapeutic options. ${ }^{26}$

The costs of such presumed false alarms were often substantial. Residents reported spending considerable time looking into the situations causing the alerts. In addition, the large number of clinically irrelevant messages reduced the credibility of the program, especially in the eyes of experienced physicians. At the completion of the study, less than a quarter of the clinicians said that the messages influenced their prescribing decisions. Nor did prescribing practices change. ${ }^{26}$ Thus, the challenges facing unvalidated systems of drug-utilization review are similar to the problems with experimental computer-assisted diagnosis that have been previously described - for example, questionable clinical relevance of diagnoses, inconsistent knowledge bases, and incomplete data on patients. ${ }^{27}$

\section{UNDERUSE OF DRUGS}

Because of limitations in the technology and data (e.g., incomplete or absent diagnoses) associated with drug-utilization review and because of cost-containment imperatives, there has been an emphasis on errors of commission, whereas problems associated with the underuse of effective medications have been virtually ignored. ${ }^{28}$ Omissions of needed drugs, for example, are inherently harder to identify than interactions between drugs. A recent analysis of drug-utilization review in three states indicated that less than 1 percent of potential drug-therapy problems identified by the computer were related to underuse. ${ }^{29}$ However, recent research indicates that some of the most debilitating, costly, and treatable illnesses are undertreated. The underuse of antihypertensive drugs (e.g., through noncompliance) has been associated with increases in hos- 
pital admissions. ${ }^{30,31}$ In several large studies in the United States, less than half the patients with serious depression received effective medication or at least short-term psychotherapy. ${ }^{32}$ At one teaching hospital, one third of patients with acute myocardial infarction who were eligible for treatment with beta-blocker drugs did not receive any of those drugs, contrary to the guidelines of the American College of Cardiology. As a result, the mortality rate among these patients was 20 to 40 percent higher than that among patients given a beta-blocker. ${ }^{33}$ Moreover, most programs of drug-utilization review do not address problems caused by patients' behavior, including prescriptions for refills of essential drugs that have gone unfilled.

Recent studies suggest that common policies for containing drug costs can also result in the underuse of effective medications, adverse clinical outcomes, and increased expenditures. For example, a Medicaid policy that limited drug reimbursement to no more than three drugs reduced the extent to which frail elderly and chronically mentally ill patients in the community were treated with essential somatic and psychotropic medications. The policy also increased the rates of institutionalization in nursing homes, emergency mental health visits, and full-day or half-day hospitalizations in community mental health centers - all at costs far in excess of the drug savings. ${ }^{34-36}$ Placing the primary emphasis on errors of commission is therefore a major weakness of current efforts to review drug use. ${ }^{15,37}$

\section{Risks of Denying Prescribed Drugs}

Computer-based drug-utilization review can have educational functions (e.g., by providing information on appropriate dosages), but denying patients specific drugs at the point of sale may present unintended risks. For example, a program that reimburses the costs of medications for the elderly in Pennsylvania recently used its system of prospective drug-utilization review to refuse to fill prescriptions for the benzodiazepine triazolam (Halcion) if a patient had received that drug for three consecutive months. ${ }^{38}$ Although some long-term benzodiazepine treatment leads to habituation and represents inappropriate prescribing, denying the drug may violate the patient's privacy and cause the adverse effects of rapid withdrawal. ${ }^{39}$ Confronting the patient in the pharmacy in this manner is an insensitive and ineffective form of drug-abuse counseling.

Computer-based systems have also been used to deny refills of medications to patients who request them seven days or more before the anticipated refill date. Between January and October 1993, for example, 144,880 requests for early refills were denied in Maryland. ${ }^{9} \mathrm{~A}$ recent report indicated that five Medicaid programs that screened prescriptions for early refills have realized enormous savings from such denials. ${ }^{9}$ Early refills may signal possible fraud or abuse, particularly if the drug has street value, as narcotics do, but there may be alternative explanations. The physician may have asked the patient to increase the dose of a drug without having notified the pharmacist; thus, the patient will need more of the drug sooner. Also, the patient may have misunderstood the instructions or may be able to travel to the pharmacy only when transportation is available.

Scrutiny of reports on two states arouses concern that refills are often denied for essential medications. ${ }^{9}$ In Maryland, the most common early refills requested in 1993 involved inhaled drugs for asthma and emphysema, antiulcer drugs, several antihypertensive agents, both oral and injectable antidiabetic drugs, and medications prescribed for panic attacks. Several of these drugs are given for extended periods to treat lifethreatening illnesses, and most have no potential for fraud or abuse. Similar refills were requested in Tennessee. ${ }^{9}$ In both states, over 75 percent of requests for early refills were denied. It is not known whether the prescriptions were eventually filled, whether the patients ever received these essential medications, or how much the state policies reduced patients' compliance and precipitated adverse health outcomes.

In contrast to such across-the-board administrative restrictions, substantial savings may be achieved by discouraging the use of certain expensive drugs for which there are inexpensive, equally effective, and safe alternatives. Elsewhere in this issue of the Journal, ${ }^{40}$ Smalley and colleagues report the results of a welldesigned, longitudinal study of the effects of a policy in the Tennessee Medicaid program that required prior authorization for the use of nongeneric nonsteroidal antiinflammatory drugs (NSAIDs). This prior-authorization policy achieved a 53 percent reduction in expenditures for NSAIDs, primarily through the substitution of generic agents. As a result, there was an estimated savings of $\$ 12.8$ million over a two-year period without concomitant increases in expenditures for other drugs or outpatient services.

Such carefully targeted strategies, which encourage the selection of cost-effective agents within a therapeutic category, may have implications for drug-utilization review. However, some caution is warranted. We do not know, for example, what proportion of the reported 26 percent reduction in overall use of NSAIDs by enrollees represented appropriate use by patients with painful and debilitating arthritis or another chronic condition. Nor do we know the amount of time required for physicians or pharmacists to seek prior authorization - the so-called hassle factor — that may divert their attention from more important tasks. Injudicious use of a prior-authorization policy to cover medications other than NSAIDs can be a barrier to essential care. In a study of Medicaid patients in West Virginia, ${ }^{41}$ the use of cimetidine among those with a diagnosis of peptic ulcer declined by 84 percent after the imposition of a prior-authorization requirement - at a time when there were no effective therapeutic alternatives. Although the design of this study precluded a 
valid assessment of the health and economic consequences of reduced access to histamine $\mathrm{H}_{2}$ antagonists (e.g., increased hospitalizations), cases such as this underscore the need to monitor carefully the effects of drug-related policies on systemwide costs, quality, and outcomes of care.

\section{Conflicts OF INTERest}

Few would disagree that the primary goal of drugutilization review - disseminating impartial information on drugs in order to increase the safety and cost effectiveness of treatment - should be educational. To achieve this goal, the data arising from such reviews must come from a source that is credible, authoritative, and accountable to physicians and the public. ${ }^{11}$ This requires financial independence from pharmaceutical companies and other entities with vested interests in the sale of specific drugs. Recently, drug manufacturers have acquired several large pharmacymanagement companies that conduct drug-utilization reviews and manage claims, formularies, and pharmacy purchases on behalf of health insurers that cover an estimated 90 million people. ${ }^{42}$ Conflicts between the promotion of specific products and the dissemination of impartial and objective information about drugs are serious matters that merit further examination and debate.

\section{Conclusions}

Although computer-based drug-utilization review has been mandated for nationwide use in the public sector and is popular in the private sector, there are no valid scientific data to support its claimed benefit. Moreover, regulatory applications of this policy may reduce appropriate use of medications and pose risks to health and patient confidentiality. In general, the validity of the criteria used to detect problems with drug therapy is unknown. The data and experience reviewed in this article support several recommendations.

First, continued investment in existing programs of computer-based drug-utilization review should be predicated on reasonable evidence that such interventions are safe and effective (and ideally, cost effective), on the basis of experimental or quasi-experimental studies. ${ }^{43}$ Such research should examine the effects of various methods of review on both appropriate and inappropriate use of medications, cost, and health outcomes, especially among vulnerable populations (e.g., the unintended consequences of denied requests for early prescription refills). Studies should be conducted of the advertising claims made by companies engaged in drug-utilization review (e.g., claims of reduced hospital admissions) to inform public and private payers better about the services they purchase and to improve the detection of underuse of essential medications.

Second, a national consensus of experts is needed to identify the most salient problems with drug therapy from a systematic review of the scientific literature. Such a process should identify clinically important problems, doing so with acceptable levels of sensitivity and specificity and providing models for adaptation by programs at the state level. Furthermore, there is a critical need for pharmacoepidemiologic studies of the clinical and economic relevance of these criteria and their relation to patient outcomes.

Finally, all programs of drug-utilization review should disclose the source of specific therapeutic recommendations, as well as potential conflicts of interest, using the same disclosure principles that have been developed for product-specific evaluations of cost effectiveness. ${ }^{44}$ Disclosure is essential when drug-utilization review conducted by a pharmaceutical company involves drugs whose sale benefits the parent company.

The scientific base for drug-utilization review is in its infancy. Yet the stakes for patients, clinicians, and the marketplace are high. About three quarters of all visits to a physician end with a drug prescription. ${ }^{45}$ Used appropriately, medications represent some of the most cost-effective, health-promoting advances in medicine. Efforts to use computers to improve drug therapy in the private and public sectors must be made with attention to clinical, research, and policy issues so as to ensure that the benefits of the review outweigh the risks.

Harvard Medical School

Boston, MA 02115

Stephen B. Soumerai, Sc.D.

University of California

School of Pharmacy

San Francisco, CA 94143

Helene L. Lipton, Ph.D.

We are indebted to Ms. Adele Amodeo and to Drs. Patricia J. Byrns, Robert Fletcher, Harold S. Luft, Thomas McLaughlin, Robert Miller, Steven Pearson, Donald Rucker, Donna Schroeder, Milton Silverman, and Bryan Walser for their helpful comments and suggestions, and to Ms. Patricia Coray and Ms. Ann Payson for assistance in the preparation and editing of the manuscript.

Supported in part by a grant (1978233) from the Robert Wood Johnson Foundation, a grant (HSO7357) from the Agency for Health Care Policy and Research, a grant (5RO1 AG09611) from the National Institute on Aging, and the Harvard Community Health Plan Foundation.

\section{REFERENCES}

1. Omnibus Budget Reconciliation Act of 1990, Section 4401. Fed Regist 1992;57(212):49397-412.

2. 1993 HCFA statistics. Rockville, Md.: Department of Health and Human Services, 1993. (HCFA publication no. 03341.)

3. Lipton HL, Bird JA. Drug utilization review: state of the art from an academic perspective. Clin Pharmacol Ther 1991;50:616-9.

4. Rucker TD. Drug-utilization review: moving toward an effective and safe model. In: Morgan JP, Kagan DV, eds. Society and medication: conflicting signals for prescribers and patients. Lexington, Mass.: Lexington Books, 1983:25-51.

5. Wickizer TM. The effect of utilization review on hospital use and expenditures: a review of the literature and an update on recent findings. Med Care Rev 1990;47:327-63.

6. Grumback K, Bodenheimer T. Reins or fences: a physician's view of cost containment. Health Aff (Millwood) 1990;9(4):120-6.

7. Lee PR, Etheredge L. Clinical freedom: two lessons for the UK from US experience with privatisation of health care. Lancet 1989;1:263-5.

8. American College of Physicians. The oversight of medical care: a proposal for reform. Ann Intern Med 1994;120:423-31. 
9. Prescription drugs: automated prospective review systems offer potential benefits for Medicaid. Washington, D.C.: General Accounting Office, 1994. (GAO/AIMD-94-130.)

10. Walser BL. Pharmaceutical cost containment and quality assurance: trends in outpatient review programs and pharmaceutical benefits management. Basel, Switzerland: Hoffmann-LaRoche, 1994.

11. Soumerai SB, Avorn J. Principles of educational outreach ('academic detailing') to improve clinical decision making. JAMA 1990;263:549-56.

12. Soumerai SB, McLaughlin TJ, Avorn J. Improving drug prescribing in primary care: a critical analysis of the experimental literature. Milbank Q 1989; 67(2):268-317.

13. Drug utilization review. Issues Answers 1990;1(2):4-15.

14. LeGrady D. The Nebraska Medicaid Drug Utilization Review Program. Nebr Med J 1992;77(1):3-6.

15. Soumerai SB, Ross-Degnan D. Experience of state drug benefit programs. Health Aff (Millwood) 1990;9(3):36-54

16. Lipton HL, Bird JA. Drug utilization review in ambulatory settings: state of the science and directions for outcomes research. Med Care 1993;31:106982.

17. Groves RE. Therapeutic drug-use review for the Florida Medicaid program. Am J Hosp Pharm 1985;42:316-9.

18. Soumerai SB, Ross-Degnan D, Fortess EE, Abelson J. A critical analysis of studies of state drug reimbursement policies: research in need of discipline. Milbank Q 1993;71(2):217-52.

19. Jay ED, Eynon BP, Javitz HS. The Medi-Cal therapeutic drug utilization review project: quarterly report and final analysis report. Menlo Park, Calif.: SRI International, 1991.

20. Ray WA, Griffin MR, Schaffner W, Baugh DK, Melton LJ III. Psychotropic drug use and the risk of hip fracture. N Engl J Med 1987;316:363-9.

21. Marcus FI. Pharmacokinetic interactions between digoxin and other drugs. J Am Coll Cardiol 1985;5:Suppl A:82A-90A.

22. Rodin SM, Johnson BF. Pharmacokinetic interactions with digoxin. Clin Pharmacokinet 1988;15:227-44.

23. Rodin SM, Johnson BF, Wilson J, Ritchie P, Johnson J. Comparative effects of verapamil and isradipine on steady-state digoxin kinetics. Clin Pharmacol Ther 1988;43:668-72.

24. Mullinex SC. Drug utilization review for Iowa's Medicaid assistance program: annual progress report and evaluation, 1989. Des Moines: Iowa Department of Human Services, 1989.

25. Lezotte DC, Bondy J, Byrns PJ. Accuracy issues for computer-based DUR screening programs in the face of referent test errors. Presented at the International Society of Statisticians, Venice, Italy, August 15, 1993. abstract.

26. Lipton HL, Byrd JA. Reducing geriatric prescribing problems: two approaches. Presented at the American Public Health Association Annual Meeting, Medical Care Section, Washington, D.C., November 1, 1994. abstract.

27. Kassirer JP. A report card on computer-assisted diagnosis — the grade: C. N Engl J Med 1994;330:1824-5.
28. Soumerai SB, Lipton HL. Evaluating and improving physician prescribing. In: Strom BL, ed. Pharmacoepidemiology. 2nd ed. Chichester, United Kingdom: John Wiley, 1994:395-412.

29. Moore WJ. Medicaid drug utilization review: a critical appraisal. Med Care Rev 1994:51:3-37.

30. Stason WB, Weinstein MC. Allocation of resources to manage hypertension. N Engl J Med 1977;296:732-9.

31. Maronde RF, Chan LS, Larsen FJ, Strandberg LR, Laventurier MF, Sullivan SR. Underutilization of antihypertensive drugs and associated hospitalization. Med Care 1989;27:1159-66.

32. Depression Guideline Panel. Depression in primary care. Vol. 1. Detection and diagnosis. Clinical practice guideline no. 5. Rockville, Md.: Department of Health and Human Services, 1993. (AHCPR publication no. 93-0550.)

33. Horwitz RI, Viscoli CM, Clemens JD, Sadock RT. Developing improved observational methods for evaluating therapeutic effectiveness. Am J Med 1990;89:630-8.

34. Soumerai SB, Avorn J, Ross-Degnan D, Gortmaker S. Payment restrictions for prescription drugs under Medicaid: effects on therapy, cost, and equity. N Engl J Med 1987;317:550-6.

35. Soumerai SB, Ross-Degnan D, Avorn J, McLaughlin TJ, Choodnovskiy I. Effects of Medicaid drug-payment limits on admission to hospitals and nursing homes. N Engl J Med 1991;325:1072-7.

36. Soumerai SB, McLaughlin TJ, Ross-Degnan D, Casteris CS, Bollini P. Effects of limiting Medicaid drug-reimbursement benefits on the use of psychotropic agents and acute mental health services by patients with schizophrenia. N Engl J Med 1994;331:650-5.

37. Lipton HL, Byrns PJ, Soumerai SB, Chrischilles EA. Pharmacists as agents of change for rational drug therapy. Int $\mathbf{J}$ Technol Assess Health Care (in press).

38. Pennsylvania PACE's Halcion prospective DUR has cut claims by $95 \%$ within the first two months: pharmacy reports 1992. The Green Sheet 1992; 41(17):3.

39. Shader RI, Greenblatt DJ. Use of benzodiazepines in anxiety disorders. N Engl J Med 1993;328:1398-405.

40. Smalley WE, Griffin MR, Fought RL, Sullivan L, Ray WA. Effect of a priorauthorization requirement on the use of nonsteroidal antiinflammatory drugs by Medicaid patients. N Engl J Med 1995;332:1612-7.

41. Bloom BS, Jacobs J. Cost effects of restricting cost-effective therapy. Med Care 1985;23:872-80.

42. Muirhead G. The ABCs of PBMs. Drug Topics. September 5, 1994:67-8, 73$4,76-8,80$.

43. Cook TD, Campbell DT. Quasi-experimentation: design \& analysis issues for field settings. Boston: Houghton Mifflin, 1979.

44. Kassirer JP, Angell M. The Journal's policy on cost-effectiveness analyses. N Engl J Med 1994;331:669-70.

45. Cypress BK. Drug utilization in general and family practice by characteristics of physicians and office visits: National Ambulatory Care Survey. Washington, D.C.: National Center for Health Statistics, 1983:87. 